\title{
Can lactate dehydrogenase (LDH) be used as a marker of severity of pneumonia in patients with renal transplant?
}

\author{
Carlos M. Luna, María M. Perín \\ Pulmonary Diseases Division, Hospital de Clínicas, Universidad de Buenos Aires, Buenos Aires, Argentina \\ Correspondence to: Carlos M. Luna, MD, PhD. Pulmonary Diseases Division, Hospital de Clínicas, Universidad de Buenos Aires, Arenales 2557 , Piso \\ 1 Dep A, 1425, CABA, Buenos Aires, Argentina. Email: dr.cm.luna@gmail.com. \\ Provenance and Peer review: This article was commissioned by the editorial office, Annals of Translational Medicine. The article did not undergo external \\ peer review. \\ Comment on: Su Y, Ju MJ, Ma JF, et al. Lactate dehydrogenase as a prognostic marker of renal transplant recipients with severe community-acquired \\ pneumonia: a 10-year retrospective study. Ann Transl Med 2019;7:660.
}

Submitted Feb 08, 2020. Accepted for publication Mar 16, 2020.

doi: $10.21037 /$ atm-2020-34

View this article at: http://dx.doi.org/10.21037/atm-2020-34

The development of immunosuppression during the last decades improved the graft survival but increased the susceptibility to infections after solid organ transplant. Pneumonia is a very frequent infection in patients with renal transplant $(1,2)$, and bacterial etiology remains the most common cause of both, nosocomial, and community acquired pneumonia (CAP), in those patients $(3,4)$. The incidence of pneumonia after kidney transplantation has been estimated to be, between $9 \%$ and $18 \%(5,6)$. Early after transplant, there is an increased risk of nosocomial pneumonia due mainly to multi-resistant gram-negative bacilli including Klebsiella pneumoniae and Pseudomonas aeruginosa, and gram-positive cocci, particularly Staphylococcus aureus and less frequently Streptococcus pneumoniae. Later, particularly during the first 6 months following transplantation, communityacquired bacteria (Streptococcus pneumoniae, Haemophilus influenzae, Mycoplasma, Chlamydia and Legionella) are the usual causative organisms, but opportunistic pathogens in relation with the immunosuppression, may appear. Pneumonia occurring in kidney transplant receptors are associated with high morbidity and mortality (4). During the immunosuppression, especially in the late period that occurs after a few years after the transplant, in the context of chronic immunosuppression pneumonia can also be caused by low virulence bacteria that do not produce this disease in the immunocompetent host. The diagnosis of pneumonia due to those opportunistic organisms in these patients usually delays the initiation of an appropriate therapy and results in an increase of morbidity and mortality due to this lung infection $(5,6)$. The radiologic features could be atypical, pulmonary infiltrates could be due to different causes, approximately one-third of those infiltrates in these patients are non-infectious $(7,8)$.

Severe CAP is a common way of presentation in kidney transplant patients and is complicated with higher morbidity and mortality rates, even when there have been important advances in the management of these patients (9-11).

Among the parameters potentially useful as predictors of outcome in renal transplant patients with pneumonia, those related with renal function, the clinical pneumonia scoring systems and the biomarkers should be taken into consideration. Regarding with renal function, low baseline estimated glomerular filtration rate (EGFr) has been found to be associated with mortality following CAP and sepsis, however it has been rarely examined according to clinically meaningful categories of EGFr (12). In relation to the scoring systems Pneumonia Severity Index (PSI) and CURB-65, they were designed to be used to assess severity of pneumonia, in immunocompetent patients those with a score $>2$ were found to be at a high risk of death. However, in immunosuppressed patients, mortality rate was found to be higher than in those immunocompetent for each of the classes of these scores (area under the curve 0.62 and 0.67 respectively) (13). About biomarkers, they have been proposed as indicators of severity, as a tool to differentiate bacterial from viral infection and to decide to stop the administration of antimicrobials. Different biomarkers, 
including C-reactive protein (CRP) and procalcitonin (PCT), are used in the evaluation of the severity of illness and predicting the outcome in CAP (14-18).

The appearance of an acute phase reaction involving cytokines and the occurrence of hepatic metabolic changes are associated with the increased or decreased concentration of acute phase proteins (APPs), associated with function alteration and pathology. The decrease of the concentration of albumin level is considered a negative APP, and has been associated with functional impairment, severity of illness and death in several conditions including pneumonia (19). On the other hand, high CRP and PCT level, have been suggested to be associated with bacterial etiology, severity of illness and death in patients with CAP $(20,21)$.

Kamat $e t$ al. in a systematic review and meta-analysis found that serum PCT levels do not have sufficient sensitivity or specificity to distinguish bacterial from viral CAP (12). Little is known about the relationship between the presence of the positive APPs CRP and PCT with death from pneumonia in transplant recipients. Savaş Bozbaş et al. (22) observed in 86 patients who underwent solidorgan transplant (including 44 with renal transplant), although there was a significant correlation between serum levels of PCT and CRP $(r=0.45 ; \mathrm{P}<0.001)$ and neutrophil count $(r=0.24 ; \mathrm{P}=0.025)$. There was no correlation between mortality and PCT level or CRP level $(\mathrm{P}>0.05)$.

Scores and biomarkers have not been used routinely in the evaluation of severity and outcome of CAP in immunocompromised patients and do not necessarily would work in renal transplant patients in the same way as they do in immunocompetent individuals. Having new data capable of clarifying whether the patient has a more serious clinical picture and is at risk of death can improve the management of them (23).

Su et al. performed a retrospective study on 77 renal transplant recipients who were admitted with severe CAP, in which the concentration of lactate dehydrogenase $(\mathrm{LDH})$ on day 1 and day 3 were recorded and recorded their 90-day mortality. They found that the LDH level was significantly higher on day 1 in non-survivors and the same happened on day 3. Analyzing the of LDH kinetics from day 1 to day 3 , they observed an increase of its concentration in non survivors and a decrease in survivors, and; they confirmed these findings in a multivariate analysis and concluded that they were independently associated with 90-day mortality (24). These findings are in line with a study by Ewig et al., who observed near 15 years ago that the increase of serum
LDH concentration was useful to determine the severity of disease in lung parenchyma and the inflammation in pneumonia who was associated with a higher mortality (25). Although LDH is a recognized marker of the presence of an infection due to Pneumocystis jiroveci in immunocompromised patients including those who received renal transplantation, its incidence has been reduced with prolonged use of prophylaxis with trimethoprim-sulfamethoxazole (TMP-SMX) (26).

This concept of using LDH concentration as a biomarker of pneumonia in renal transplant recipient was catched by Liu et al., who developed a score that they called "expanded-CURB-65 score", defined by using the CURB65 score factors plus $\mathrm{LDH}>230 \mu / \mathrm{L}$, albumin $<3.5 \mathrm{~g} / \mathrm{dL}$ and platelet count $<100 \times 10^{9} / \mathrm{L}$, which proved to be simpler and more effective in 1,640 consecutive hospitalized CAP patients in predicting mortality than the pneumonia severity scores (27).

LDH is a cytoplasmatic enzyme expressed in nearly all types of cells of the body. It is released into blood when cell experiences injury or death caused by ischemia, excess heat or cold, starvation, dehydration, injury, bacterial toxins, drugs and chemical poisonings (28). Su et al. demonstrated that serum LDH elevated post renal transplant could be used as a marker of severe pneumonia in transplant patients (24). But it is necessary also to consider that different conditions potentially associated with increased level of LDH, including posttransplant lymphoproliferative disorder, P. jiroveci pneumonia, thrombotic microangiopathy-hemolytic uremic syndrome, acute renal infarction or hemolytic anemia from dapsone (alternative to TMP-SMX for prophylaxis against $P$. jiroveci), represent diagnostic and clinical challenges that could be involved in the care of renal transplant patients (29).

$\mathrm{LDH}$ have demonstrated in the past that could work as good as CURB-65 and PSI or CRP and PCT or other newer APP and biomarkers to predict the outcome in CAP in general, but also in CAP occurring in patients that underwent kidney transplant. However, LDH is not used to identify the severity of illness in CAP. This seems to be the result of the progress of medicine, but it could also be considered as the result of the perception that the appearance of a newer marker makes the oldest one undesirable or non-functional, although it still works perfectly (known as perceived obsolescence).

\section{Acknowledgments}

Funding: None. 


\section{Footnote}

Conflicts of Interest: Both authors have completed the ICMJE uniform disclosure form (available at http://dx.doi. org/10.21037/atm-2020-34). The authors have no conflicts of interest to declare.

Ethical Statement: The authors are accountable for all aspects of the work in ensuring that questions related to the accuracy or integrity of any part of the work are appropriately investigated and resolved.

Open Access Statement: This is an Open Access article distributed in accordance with the Creative Commons Attribution-NonCommercial-NoDerivs 4.0 International License (CC BY-NC-ND 4.0), which permits the noncommercial replication and distribution of the article with the strict proviso that no changes or edits are made and the original work is properly cited (including links to both the formal publication through the relevant DOI and the license). See: https://creativecommons.org/licenses/by-nc-nd/4.0/.

\section{References}

1. Fishman JA. Introduction: infection in solid organ transplant recipients. Am J Transplant 2009;9:S3-6.

2. Pourmand G, Salem S, Mehrsai A, et al. Infectious complications after kidney transplantation: a single center experience. Transpl Infect Dis 2007;9:302-9.

3. Hoyo I, Linares L, Cervera C, et al. Epidemiology of pneumonia in kidney transplantation. Transplant Proc 2010;42:2938-40.

4. Wilmes D, Coche E, Rodriguez-Villalobos $\mathrm{H}$, et al. Bacterial pneumonia in kidney transplant recipients. Respir Med 2018;137:89-94.

5. Canet E, Osman D, Lambert J, et al. Acute respiratory failure in kidney transplant recipients: a multicenter study. Crit Care 2011;15:R91.

6. Dizdar OS, Ersoy A, Akalin H. Pneumonia after kidney transplant: incidence, risk factors, and mortality. Exp Clin Transplant 2014;12:205-11.

7. Sousa SR, Galante NZ, Barbosa DA, et al. Incidence of infectious complications and their risk factors in the first year after renal transplantation. J Bras Nefrol 2010;32:75-82.

8. Ingsathit A, Avihingsanon Y, Rattanasiri S, et al. Different etiologies of graft loss and death in Asian kidney transplant recipients: a report from Thai Transplant Registry.
Transplant Proc 2010;42:4014-6.

9. Viasus D, Garcia-Vidal C, Cruzado JM, et al. Epidemiology, clinical features and outcomes of pneumonia in patients with chronic kidney disease. Nephrol Dial Transplant 2011;26:2899-906.

10. Küpeli E, Eyüboğlu FÖ, Haberal M. Pulmonary infections in transplant recipients. Curr Opin Pulm Med 2012;18:202-12.

11. Cui W, Zhao H, Lu X, et al. Factors associated with death in hospitalized pneumonia patients with 2009 H1N1 influenza in Shenyang, China. BMC Infect Dis 2010;10:145.

12. Kamat IS, Ramachandran V, Eswaran H, et al. Procalcitonin to Distinguish Viral From Bacterial Pneumonia: A Systematic Review and Meta-analysis. Clin Infect Dis 2020;70:538-42.

13. Carrabba M, Zarrantonello M, Bonara P, et al. Severity assessment of healthcare-associated pneumonia and pneumonia in immunosuppression. Eur Respir J 2012;40:1201-10.

14. Fine MJ, Auble TE, Yealy DM, et al. A prediction rule to identify low risk patients with community-acquired pneumonia. N Engl J Med 1997;336:243-50.

15. Lim WS, van der Eerden MM, Laing R, et al. Defining community acquired pneumonia severity on presentation to hospital: an international derivation and validation study. Thorax 2003;58:377-82.

16. Lee JH, Kim J, Kim K, et al. Albumin and C-reactive protein have prognostic significance in patients with community-acquired pneumonia. J Crit Care 2011;26:287-94.

17. Viasus D, Garcia-Vidal C, Simonetti A, et al. Prognostic value of serum albumin levels in hospitalized adults with community-acquired pneumonia. J Infect 2013;66:415-23.

18. Kim MW, Lim JY, Oh SH. Mortality prediction using serial biomarkers and various clinical risk scales in community-acquired pneumonia. Scand J Clin Lab Invest 2017;77:486-92.

19. Miyazaki H, Nagata N, Akagi T, et al. Comprehensive analysis of prognostic factors in hospitalized patients with pneumonia occurring outside hospital: Serum albumin is not less important than pneumonia severity assessment scale. J Infect Chemother 2018;24:602-9.

20. Krüger S, Ewig S, Pappassotiriou J, et al. Capnetz STUDY GROUP. Inflammatory parameters predict etiologic patterns but do not allow for individual prediction of etiology in patients with CAP: results from the German competence network CAPNETZ. Respir Res 2009;10:65. 


\section{Page 4 of 4}

21. Hedlund J, Hansson LO. Procalcitonin and c-reactive protein levels in community acquired pneumonia: correlation with etiology and prognosis. Infection 2000;28:68-73.

22. Savaş Bozbaş Ş, Er Dedekargınoğlu B, Ulubay G, et al. Role of Serum Procalcitonin Levels in Solid-Organ Transplant Patients. Exp Clin Transplant 2016;14:116-20.

23. Karakioulaki M, Stolz D. Biomarkers in PneumoniaBeyond Procalcitonin. Int J Mol Sci 2019;20:2004.

24. Su Y, Ju MJ, Ma JF, et al. Lactate dehydrogenase as a prognostic marker of renal transplant recipients with severe community-acquired pneumonia: a 10-year retrospective study. Ann Transl Med 2019;7:660.

25. Ewig S, Bauer T, Hasper E, et al. Prognostic analysis and predictive rule for outcome of hospital-treated community-

\section{Luna and Perín. LDH is a useful marker of pneumonia severity}

acquired pneumonia. Eur Respir J 1995;8:392-7

26. Borstnar S, Lindic J, Tomazic J, et al. Pneumocystis jiroveci pneumonia in renal transplant recipients: a national center experience. Transplant Proc 2013;45:1614-7.

27. Liu JL, Xu F, Zhou H, et al. Expanded CURB-65, a new score system predicts severity of community-acquired pneumonia with superior efficiency. Sci Rep 2016;6:22911.

28. Glick JH. Serum lactate dehydrogenase isoenzyme and total lactate dehydrogenase values in health and disease, and clinical evaluation of these test by means of discriminant analysis. Am J Clin Pathol 1969;52:320-8.

29. Boothpur R, Brennan DC. Didactic Lessons from the Serum Lactate Dehydrogenase Posttransplant: A Clinical Vignette. Am J Transplant 2008;8:862-5.
Cite this article as: Luna CM, Perín MM. Can lactate dehydrogenase (LDH) be used as a marker of severity of pneumonia in patients with renal transplant? Ann Transl Med 2020;8(15):911. doi: 10.21037/atm-2020-34 